\section{Science Students at Universities and Schools}

The National Service (Armed Forees) Act is being applied to six new age groups covering the ages 18-19 and 37-40. The existing Schedule of Reserved Occupations is also to be revised, the tendency being to make reservation depend to an increasing extent upon the actual work being done by the man for whom reservation is sought, and not simply upon his age and registered occupation. In connexion with the registration of the 19 -year-olds, arrangements are already in existence to safeguard the supply of men studying to obtain certain scientific and technical qualifications that will fit them for important national work. The University Joint Recruiting Boards have power to recommend the deferment of the calling-up of such men who are studying at universities or who are studying for a Higher National Certificate or a Higher National Diploma. These arrangements will be extended in future to young men engaged in particular scientific and technical studies who are still at school but will shortly be proceeding to universities, provided that they have obtained the Higher School Certificate or will shortly be sitting for that examination and show exceptional promise. Consideration is being given to the reservation of all medical and dental students irrespective of the stage they may have reached in their studies.

\section{Red Locust Control Organization}

THE Colonial Office announces that Mr. A. P. G. Michelmore has been appointed to the new post of locust officer in Northern Rhodesia. Mr. Michelmore, who has been serving with the Forces, has devoted some years to the study of the red locust, and in view of the importance of locust control he has been released for this work. 'The desirability of establishing control organizations in breeding areas of certain species of locusts was considered by the Fifth International Locust Conference held in Brussels in 1938, and eventually proposals for establishing these Control Organizations were put forward. In present circumstances, the red locust, the known breeding areas of which are in Northern Rhodesia and Southern Tanganyika, is the only species for which it is practicable to establish a control scheme. It is evident that the original international scope of the scheme must for the present be disregarded. The urgency of the scheme lies in the necessity for preventing, if that be possible, or at least reducing, the huge losses incurred annually by the cultivators of Africa through the depredations of locusts; at the present time, when people are more and more dependent on their own locally produced food supplies, the desirability of reducing the wastage by locusts is even more important than before.

Lord Lloyd, the Secretary of State for the Colonies, has therefore formulated under the Colonial Development and Welfare Act, 1940, a scheme for the establishment in Northern Rhodesia of a control organization, and a free grant of a sum not exceeding $£ 3,000$ has been made available to meet the capital cost. The scheme will be administered by the Government of Northern Rhodesia, but neighbouring Governments will contribute to its annual cost. The present swarming cycle of the red locust is still continuing, though there are indications that this cycle is declining, and breeding is gradually concentrating in the most favoured areas. There is, however, always the possibility that from the known permanent out break areas new swarms will emerge and reinforce those swarms of the present cycle which are dispersed. While it is not proposed that the new organization should undertake practical control in the temporary breeding areas, steps will be taken to organize observation in case such areas should develop into permanent breeding places, and investigations will be carried out into the natural conditions under which locusts breed, etc., in order that methods of prevention and control may be improved.

\section{Flight Refuelling}

IN a paper read on January 22 before the Royal Society of Arts, Sir Alan Cobham described experiments in flight refuelling that have been carried out for the last ten years. They culminated in the methor used on the Empire flying boats which were operating the Atlantic experimental services. Sixteen crossings were made by the boats Caribou and Cabot between August 5 and October 1, 1939. In one of these, refuelling was unnecessary, as there was a very strong westerly wind that helped Caribou to complete the crossing with the original take-off load of fuel. These flights have proved that the method is successful, and the equipment adequate. Mechanization of some of the units would save time and labour during the opera. tion, and suitable wireless equipment is necessary in order to ensure contact between the machines and the bases.

There is no special difficulty in using the apparatus at night, or in bad weather, as the connexion between the tanker (giver) and the air liner (receiver) is almost automatic. In fact it is claimed that flight refuelling can be carried out in any sort of weather in which air transport is possible. The general principle of the operation is that the tanker (giver) flies behind, above, and to one side of the receiving craft. The hose passes from the nose of the tanker to the tail end of the receiver's body. Thus the hose, or the contacting and hauling lines, pass over no part of either aircraft, and there is no danger of entanglement. Although refuelling after having taken off allows of an increase of 46,000-53,000 lb. weight, this by no means represents the extra load that could be carried upon an aircraft designed for the purpose. A machine of to-day, limited in loading by take-off conditions, can carry about 30-35 lb. per sq. ft. of wing area, whereas one designed for refuelling in the air, and therefore not so limited, could carry 50-60 lb. per sq. ft. in flight. The paper visualizes loadings of $80-90 \mathrm{lb}$. per sq. ft. as being practicable. Such aircraft should be capable of air ranges of 5,000 miles, and it becomes possible to link up all the important centres of the world by air lines operating at these distances between landings. 